\title{
The Dai Dance Music Analysis
}

\author{
Ji Yi \\ Qujing Normal University, Yunnan, Qujing, China, 655011 \\ qjsfxyjiyi@126.com
}

Keywords: The Dai Dance Music; Content Form; Music Analysis

\begin{abstract}
This article will be carried out on the form of the dai nationality dance music content overview and analysis, some concrete from crop simulation dance music, lyrical dance music, dance music, story and he props dance music, dance, music, martial arts dance music, ritual dance music, dance music palace for analysis. Through the study of the dai nationality dance music, literature, not only expanded its own understanding and the understanding of national music, and carry forward the national culture sense of confidence in our country, to improve their comprehension of national music, at the same time, enriched and developed their own music anthropology research.
\end{abstract}

\section{The Overview of the Dai Nationality Dance Music}

China arc mainly gathered in yunnan province western border of the dai nationality of xishuangbanna dai autonomous prefecture, dehong dai and jingpo autonomous prefecture and lincang, gengma, Meng Lian, including yuanjiang, xinping, jin, double river and so on more than 30 counties. A population of about 1.03 million (1990), the dai is a long history, the crossover and the national. In addition to the Chinese province of yunnan xishuangbanna and dehong, also in Thailand, Burma (2.5 million) (80) and Laos, Vietnam (180000). These belong to sino-tibetan strong strong zhuangdong lauguage. Of the dai nationality in xishuangbanna, pu 'er hinayana Buddhism, dehong dai religion, Buddhism, and also keep the original worship god more customs.

\section{The Content of the Dai Nationality Dance Music Form}

The dai national minority's traditional music can be divided into two major categories, folk music, religious music. There are many different kinds of folk music, folk songs, singing and dancing music, hip-hop music, opera music four categories, from the analysis on music form, all the music characteristics of each different, unique style, including folk music as the major form of the dai nationality dance music. "The dai traditional folk songs in the music plays an extremely important position. According to its category, can be divided into folk songs, narrative songs and customs, songs and nursery rhymes, toasting song, etc., are all or texture." [1] on the basis of the classification of the dai national minority tradition, the folk songs and dances include "cry to shout yellow", "light" two big kinds. Of the dai nationality folk dance music is the most commonly used in the traditional ethnic festivals "water-splashing festival" or "GanBai" (religious folk gatherings) activities.

\section{The Dai Dance Music Analysis}

The Spirit of "Sparrow" Dance Music Analysis. After 1979, the dance music quickly out of the narrow heaven and earth, composers in the art practice to deepen the understanding of dance music art rule, many works creation method of constrained under the dance moves from the past, to overcome the "pictorial" and naturalism, have the courage to break through the pure the narrative method and invariable reappearance of the folk music box, will inherit the national music heritage combined with injecting new art methods, make the logic of music performance, structure, hierarchy, artistic aspects has larger breakthrough.

Dance music "the spirit of finches" absorb and draw lessons from the importance of the dai traditional folk music elements, including the dai traditional folk songs in the form is free, not strict 
rhythm, melody rhythm also more flexible, across the many different singing. According to the different features of singing, can be divided into city folk songs, bazi folk song folk song folk song, lum, ruili, parrots (above dehong region) as well as love poems, sling, rope (xishuangbanna and Meng Lian above), and other forms. "Distinct dehong in most of the tunes, outstanding stress, glides, xishuangbanna area more grace note. The ruili folk songs is lively, bright and clear, each with its own characteristics. But overall, the dai national minority folk songs are more downy elegant style, lyrical color is strong." [2]

Folk songs, folk songs, narrative song, elegy, religion, etc. Folk songs by the youth in the field, forest solo or more men and women singing. Some love, hometown praise, happiness life, some make impromptu singing. Dehong region folk songs are "shout" and "shout with bases" two kinds. 1) lum, yingjiang, etc

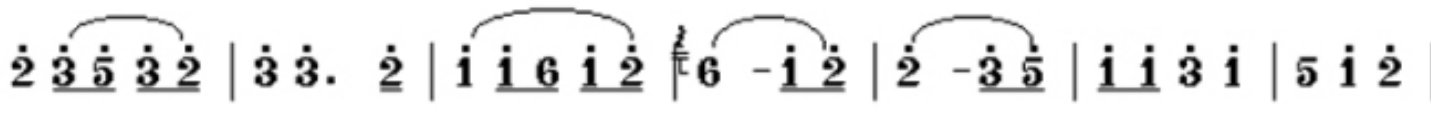

Long narrative has fixed the singing, in xishuangbanna area is known as the "chapter ha". "Chapter," dai singers singing singing with other areas there are a lot of common characteristics, such as rhythm and intonation closely, recitation and GeChangXing combine closely, it basically with pentatonic scale $(1,2,3,5,6)$ as the foundation, often use glide, grace note and tremolo, make the soft lyric singing. When the singer singing in xishuangbanna area dai national minority unique bamboo flute is commonly used in (lauguage called "bi") or approximate "with" of erhu accompaniment, multi-purpose Meng Lian area similar three-stringed "with" accompaniment. The dai lyrics word in each sentence is not fixed, the use of the word frequency is high. Long poems rhyme way roughly the same as the folk songs, and its main requirements are finals (including main vowel and terminal), the same tone of high and low, no strict rules.

"Religious song dehong region have a prayer, to chant buddhist scripture, water blessing, etc; in xishuangbanna region has prayer pitch, fast rise, the monk chanted sutras, slow to chant buddhist scripture, etc. There around also reflect the original worship to god, and the witch singing teacher niang, jump of god and the wizard's divination, etc. Their common characteristic is tone to read. In addition, songs and nursery rhymes and hypnosis, etc." [3]

Deep in the "Bamboo Forest" Dance Music Analysis and Extension. Composed by the editor Yang Zhengxi hulus repertoire deep "bamboo forest" has become a typical representative of the dai nationality dance music works. Using hulus timbre and technique to create unique lingering long flowing melody, will the dai national character of the water, peaceful and harmonious life picture show incisively and vividly.

According to the popular music in dehong yunnan region "gourd xiao song creation. Dai XiaoBuMao (lad) in the night "string" girl (love) when playing hulus gourd shaw, adjustable, XiaoBuShao (girl) can tell their lovers according to different tone. The song and its lyrical melody style, showing the love life of the dai young people. The mainly express dai XiaoBuMao (lad) and XiaoBuShao (girl) to fall in love in the moonlight and bamboo forest. Beginning is XiaoBuMao blow hulus under the bamboo forest, in the bamboo house heard gore silk slowly went down after a meeting with XiaoBuMao, then two people hand in hand into the depths of the bamboo forest, play boy, girl jumped pavan, tune lively, jumping end part is long and slow tone, express the situation of boys see girls home when coming.

"Song and dance music including the peacock song, drums, twelve horses, shout according to restore, firm, etc. In the festival, GanBai, singing festival, multi-purpose elephant-foot drum percussion accompaniment." [4] (1) the peacock song, say these "shout rayong", popular indica region, singing with the peacock dance performances by. Music fast active, mostly mode. (2) play the drums, lauguage said shout "sea ray", popular indica lum, covering area, points with drum tuning (shout this light) and with drum rap (shout lamp light) two, both music approximation, the former with GongDiaoShi $(1,2,3,5,6)$, the latter with characteristics of mode $(5,6,7,2,3)$; Singing and dancing with. (3) twelve horses, lauguage said "call fine double horse", popular in yingjiang, lianghe, etc. By 12 young men and women put on bamboo color ZhiMa song and dance, young people meet on the way GanBai song performance and production activities in the 12 months 
each year. Melody lyric, for more business mode. (4) based on restore is a kind of mass song and dance, popular in xishuangbanna. Water-sprinkling festival every year acetate ship firecrackers, long, people dance and sing, a warm atmosphere. Basic is 3 words and music plain, much by plume mode of three or four note column. (5) shout, singing and dancing for the stage, the original is the melody in Burma the dai national minority folk song and dance drama, also in ruili area in our country. With the sound of the seven GongDiaoShi or mode. The tune lively, fresh, unique style. Dehong region the elephant-foot drum dance in addition to the above for all kinds of dance music, the dai national minority area has a variety of folk dance, popular, such as the elephant-foot drum dance, pavan, fish dance dance dance, red deer, gong and other variety of inspiration, etc., all with percussion accompaniment.

\section{The Cucurbit Flute Dance Music Analysis.}

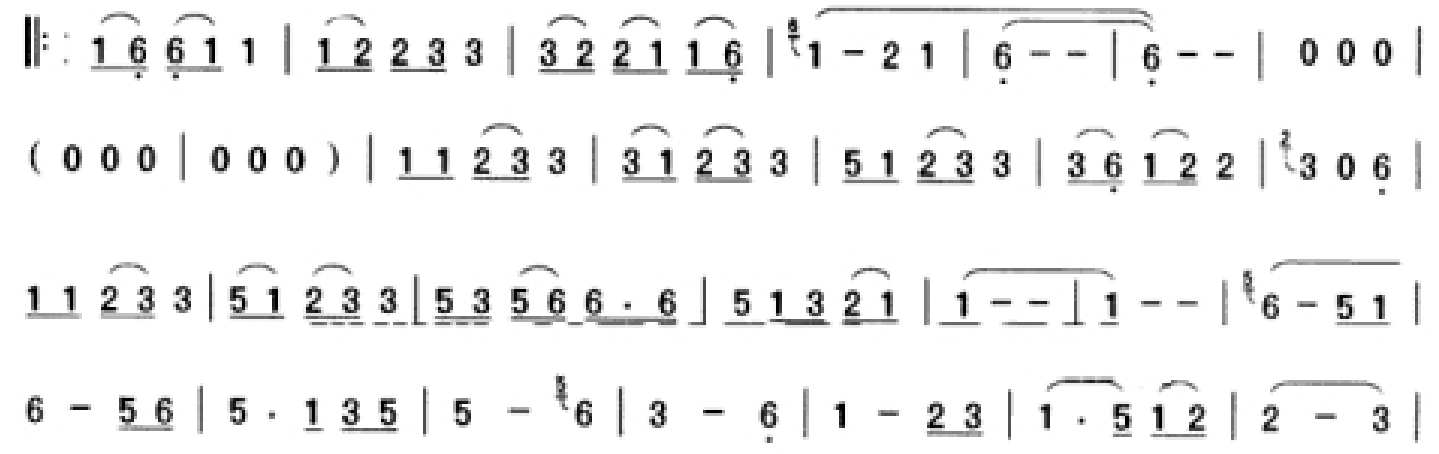

Under the moonlight cucurbit flute, gently beautiful like green fog, the good girl in the bamboo house, sparkling like a pearl......" Dai violin cucurbit flute is a song, national sentiment, with its melodious tunes, beautiful expression of melody, give a person the feeling of find the scenery pleasing to both the. Make up with the bamboo lush PND tail-on unique dai pavilions scattered in the bamboo forest, like a celestial planetesimals, mountain, in the moonlight, happy and faint sounds of hulus trail in the bamboo forest, deep and remote togeher the rise and fall, light quietly elegant.

Low, rising and falling, euphemism, hulus music, is so intoxicating, bright moon, ruili river flowing quietly, water in the silver moonlight and sparkling, water-like moonlight, quietly spilled on pieces of cucurbit flute, jagged mottled do swaying in the wind. The light wind gently brushed cucurbit flute, far look like a layer of green fog in dancing, in the bamboo house beautiful a-mei are deep feeling of stare out of the window, outside the bamboo house spoony brother love hulus sound, in the quiet night more lingering, is talk with each other in the heart of love.

The cucurbit flute dance music also absorb and draw lessons from the dai traditional folk rap music elements like "ha". Chinese translation of "praise ha" to "singing artist", Meng Lian area known as the "nest gump". Wow ha is kind of a semi-professional folk rap artist, is also a form of folk rap music. Praise, usually in the water-sprinkling festival, marriage, birth, build new homes, especially in ceremony for improvisational singing. In xishuangbanna dai national minority folk, who were divided into "ha $\mathrm{Bi}$ " (i.e. Bi accompaniment of praise, adjustable) and "with" (west accompanied with the praise of adjustable) two kinds.

"Rap music major epidemic in xishuangbanna and Meng Lian. The dai people in every family holidays, build the bridal chamber, weddings, ceremony activities, invite folk singer singing. Present the semi-professional artists in xishuangbanna said" ha ", said in Meng Lian "nest gump. Strains circulating around one like" ha ", "nest gump", "Meng Lian" etc." [5] sung by one person, a person to accompany, accompaniment instrument with $\mathrm{Bi}$, west with respectively, tune close integration with the language, the rhythm is smooth, the change of basic music structure is passages repeatedly, lyrics waist rhymes. Due to the structure of the lyrics is free, so the number of phrases and length is not fixed; Instrument accompaniment and singing voice often form a sound polyphony relations. Opera music DaiJu is on the basis of the dai national minority folk song and dance music, and draw lessons from the art of the han drama performance means, spread of indica, baoshan, lincang, etc. The dai national minority areas. DaiJu includes a variety of men and women singing, 
male cavity mode of the multi-purpose feather, female cavity multi-purpose mode. Since the $1950 \mathrm{~s}$, DaiJu absorb a variety of dai national minority folk song and dance, enrich the singing, enhancing the music's expressive force. DaiJu singing is basic sentence composed of passages and its change over and over again. Due to the lyrics may be less than, so the phrase length different singing. In the past, DaiJu only small tupan, gongs, cymbals, such as accompaniment, after gradually USES a variety of ethnic Musical Instruments and western orchestral instruments, form new DaiJu band. "The dai ethnic Musical Instruments belong to play Musical Instruments have Bi gourd, flute, vertical, flute, konoha, etc; plucked string instruments with a harp, etc. in 1910, yingjiang toast organized the first professional DaiJu group, on the basis of the dai national minority folk songs and dances and folk songs, absorb the Peking Opera and yunnan opera repertoire, performance programs, costumes, props, percussion, and other forms of art, and adaptation, a new DaiJu ChuangYan dramas. "DaiJu music turned out to only small tupan, tupan, gongs, cymbals and so on percussion accompaniment, now the professional troupe has been used in the national orchestra (Bi, along with, bamboo flute, erhu, etc.). The more famous DaiJu dramas have the moths and SangLuo," lotus ", the drama of xishuangbanna "ah is lifted up" (catch traitors) and adaptation, transplantation plays "white snake", "water margin", the romance of The Three Kingdoms, "the siege", "the red lantern" and so on." According to preliminary statistics, dehong DaiJu plays a total of more than three hundred, is divided into three types: one is the transplant, is based on zhanghui novel, fictions and han drama translation, an adaptation. Such as "granting titles to gods", "tao HeSheng", "han wu light", "wang zhaojun", "east of xue li levy," Xue Dingshan levy west ", "white snake", "butterfly", "under emperor qianlong jiangnan" and so on, this kind of play has 190. Secondly, the traditional drama, it is according to the buddhist stories, folk narrative poem, folklore and adapted the story DaiJu repertoire. Such as process o (meng), "LanGa west," process o < that $>$, "with the moths and SangLuo", "lotus", "sea Abraham", etc., there are 69. Such plays reflect the victory of justice over evil, and the dai people's aspirations, which embodies the typicality of DaiJu and nationality. Three new DaiJu, liberation transplantation or new creation in the dai national minority drama depicting the real life, there are more than 50, known as the "new DaiJu". Created to carry on the revolutionary tradition education such as the $1950 \mathrm{~s}$ the Liu Jiemei regiment haun, against arranged marriage celebrate new new thing "soft chun", praising the dai national minority female militia "on the border with which it is to catch enemy spy. "New DaiJu mostly drawn from real life, the innovation, has the strong sense of time."

\section{The Development Direction of The Dai Nationality Dance Music}

For the dai national minority music is constantly improving and developing, the dai people have a passion for singing, dancing, the creation of the traditional music culture, for the dai national minority's own traditional and national character, the dai national minority music has its own unique characteristics, their understanding and contact with southeast Asia similar to that of the dai national minority music language, it is difficult to absorb and combine the traditional national culture, this needs us in the discussion that the dai national minority folk music to do research for a long time. Contents and forms of the first in this paper for the diversification of the dai nationality folk music to have in-depth analysis, from the folk songs, singing and dancing music, hip-hop music, opera music four aspects has made the analysis and discussion, based on the four kinds of form of music content, method, characteristics of melody, modal tonality, music style and other aspects, the macro expounds the content of the dai nationality folk music, make have a comprehensive understanding, to maintain its unique national characteristics, can also absorb foreign advanced culture, can make the dai national minority folk music to seek development.

Above all: Music is without borders, as yunnan dai and music, people should take the modernization of the dai national minority music as a project to develop national culture, with his back against a powerful and rich Chinese culture and many national culture, can gain enormous energy, brave in southeast Asia tens of millions of the dai's enormous market, gave birth to the yunnan dai national minority music road to modernization. 


\section{Conclusions}

This thesis is involved in the study of the cultural consciousness and cultural confidence of the musical anthropology--Taking Yunnan Province as an example, the project number 2013QNO23

\section{References}

[1] Li-Ying S. Yunnan National Culture Unique Knowledge. London: Yunnan University Press, 2007, (3): 94.

[2] Ceng-An X. Xishuangbanna Dai National Minority Folk Music Research. Beijing: China Federation Of Publishing House, 2007, (6) : 201.

[3] Min-Kang Y. Mr. Hare - Dai's Southern Buddhism Festival Ritual Music Research. Yunnan: Religious Culture Press, 2003, (1): 53.

[4] Gong-Jin Z, Wang Feng. Dai Religion and Culture. Beijing: Central University For Nationalities Press, 2002, (9): 93.

[5] For Yang. Selected Works Of Yunnan Ethnic Music Study. Journal Of Yunnan, Yunnan People's Publishing House, 2002, (1): 189. 